\title{
El fracaso internacional del independentismo catalán: causas jurídicas y políticas
}

\author{
The international failure of the Catalan independence movement: \\ legal and political causes
}

\author{
Rafael CALDUCH CERVERA \\ Catedrático de Derecho Internacional y Relaciones Internacionales \\ Universidad Complutense de Madrid \\ rafacald@ucm.es
}

Resumen: El proceso secesionista unilateral de Cataluña, promovido desde los poderes autonómicos y apoyado por una parte de la sociedad, se desarrolló durante 2017 siguiendo una estrategia política que aspiraba a repetir el modelo de la declaración unilateral de independencia de Kosovo, en la que el apoyo y reconocimiento internacional constituyeron la clave de su éxito. No obstante la iniciativa internacional catalana cometió importantes errores jurídicos y políticos que se revelaron decisivos para su fracaso. En el ámbito de la legalidad y con la finalidad de eludir el ordenamiento español, quiso imponer una interpretación del derecho de libre determinación de los pueblos contraria a lo establecido por las normas internacionales y la práctica de los Estados. En el ámbito de la política internacional, basó su proyección exterior en una combinación de propaganda mediática y diplomacia pública para presionar a los gobiernos de las grandes potencias y a las instituciones europeas, subestimando la importancia de los compromisos e intereses establecidos con el Estado español. Finalmente, trató de fundamentar internacionalmente la aspiración secesionista recurriendo a una legitimidad democrática que la realidad política de Cataluña no avala electoralmente. El resultado final ha sido un fracaso del proceso secesionista que ha generado un aumento de la tensión social y la inestabilidad política en España y en Cataluña, demorando así la solución de un problema político que no se puede ignorar aunque todavía no se puede resolver.

Palabras clave: Cataluña; España; derecho internacional; secesión; libre determinación; política internacional.

\begin{abstract}
The unilateral secessionist process of Catalonia, promoted by the autonomic powers and supported by a part of society, was developed during 2017 following a political strategy that tried to repeat the model of unilateral independence declaration of Kosovo, in which the support and international recognition were the key to its success. However, the Catalan international initiative made important legal and political mistakes that were decisive for its failure. In the legal field and with the purpose of avoiding the Spanish system, it wanted to impose an interpretation of self-determination right opposed to establish by the international norms and the practice of States. In international politics, its foreign projection was based on a combination of media propaganda and public diplomacy to pressure the governments of great powers and European institutions, devaluing the importance of their commitments and interests established with the Spanish State. Finally, an attempt was made to base internationally the secessionist aspiration by resorting to a democratic legitimacy that political reality of Catalonia does not endorse electorally. The result has been a failure of secessionist process that has generated an increase in social tension and political instability in Spain and Catalonia, thus delaying the solution of a political problem that cannot be ignored although it still cannot be resolved.
\end{abstract}

Keywords: Catalonia; Spain; International Law; Secession; Self-determination; International Politics

Sumario: 1. INTRODUCCIÓN. 2. LA INTERNACIONALIZACIÓN DEL SECESIONISMO DE CATALUÑA. 3. ¿DERECHO A LA AUTODETERMINACIÓN O DERECHO A LA SECESIÓN? 4. EL EJERCICIO DEL «SUPUESTO» DERECHO A LA SECESIÓN UNILATERAL DE CATALUÑA: OBSTÁCULOS JURIIDICOS Y POLITICOS. 5. EL FRACASO DE LA ESTRATEGIA INTERNACIONAL DEL GOBIERNO INDEPENDENTISTA CATALÁN. 


\section{INTRODUCCIÓN}

L a política es aquella dimensión de una sociedad que establece y sustenta el necesario orden de convivencia común, gracias al cual las personas y las colectividades pueden desarrollar su vida y sus relaciones mutuas. El Estado, como realidad política, se constituye como la organización institucional y jurídica del orden de convivencia común de una determinada sociedad. Si la sociedad se fractura por enfrentamientos políticos, económicos o culturales, el orden común de convivencia se verá amenazado y el Estado deberá restaurarlo ya que corre el riesgo de desaparecer o convertirse en un Estado fallido.

Toda sociedad organizada funcionalmente requiere la implantación de un sistema jurídico, que regule las relaciones entre sus miembros definiendo derechos y obligaciones. Gracias a las normas jurídicas, las relaciones sociales pueden desenvolverse con seguridad y se pueden prever sus efectos.

Estas reflexiones iniciales, aunque resultan evidentes, conviene recordarlas cuando abordamos el estudio de la Sociedad Internacional, una sociedad dominada por la dispersión del poder en una heterogénea pluralidad de actores entre los que destacan los Estados, pero también lo son cuando analizamos los procesos secesionistas, como el acaecido en Cataluña.

En la Sociedad Internacional, el desarrollo y gestión del orden común de convivencia, es decir la política internacional, plantea importantes retos en sus tres categorías fundamentales de cuestiones: a) la gobernanza; b) la legalidad y c) la seguridad ${ }^{1}$.

Por ello el análisis de las normas jurídicas internacionales y su práctica por los Estados, debe siempre incardinarse en el marco de su dialéctica conexión funcional con la particular organización internacional del poder y con la evolución del uso de la fuerza. Como señalaba certeramente Carrillo Salcedo:

«En este orden de cosas, es indispensable que no pretendamos comprender y explicar el Derecho internacional en función del modelo de los ordenamientos jurídicos estatales, como si el Derecho interno fuese la única manifestación posible del fenómeno jurídico. Como todo ordenamiento

1 Para un estudio más detallado de las tres dimensiones básicas de la política internacional véase: CALDUCH, R. «Dilemas de la política internacional: gobernabilidad y seguridad», en FUNDACIÓN Seminario de Investigación Para la PaZ (coord.), Propuestas para una agenda de paz, Zaragoza, Departamento de Educación, Cultura y Deporte, Gobierno de Aragón, 2005, pp. 287-315. 
jurídico. el Derecho internacional dispone de normas que regulan las relaciones entre sus sujetos, sus derechos y obligaciones así como de principios, reglas y procedimientos relativos a cómo se elaboran y aplican las normas y cuáles son las reacciones que legítimamente son posibles en los supuestos de incumplimiento de las reglas jurídicas. Lo que ocurre es que, en principio y a diferencia de lo que pasa en los ordenamientos jurídicos de los Estados, estos procedimientos, principios y reglas no tienen carácter institucionalizado. Esto no significa, sin embargo, que el Derecho internacional no sea Derecho, ni tampoco que sea un Derecho primitivo, sino que es todavía, al menos en gran parte, el ordenamiento jurídico de un medio social descentralizado y escasamente institucionalizado.» ${ }^{2}$

\section{LA INTERNACIONALIZACiÓN DEL SECESIONISMO DE CATALUÑa}

El proceso secesionista de Cataluña forma parte de un largo período de reivindicaciones independistas en el Estado español, arraigadas históricamente en los nacionalismos decimonónicos aunque su desarrollo tendrá lugar a lo largo del siglo XX.

El independentismo catalán ya realizó un primer intento de secesión unilateral en octubre de 1934 al declarar el Presidente de la Generalitat, Lluis Companys, el Estado Catalán como parte de una futura República Federal Española. El intento fracasó inmediatamente por la intervención del ejército republicano.

Durante la época franquista, se creó en 1964 el Movimiento para la Autodeterminación e Independencia del Archipiélago Canario (MPAIAC). Paralelamente en el País Vasco la organización política Euskadi Ta Askatasuna (ETA), escisión radicalizada del Partido Nacionalista Vasco, iniciaba su estrategia terrorista que perduraría medio siglo ${ }^{3}$.

Han debido transcurrir más de ocho décadas para que los partidos políticos independentistas de Cataluña realizasen un nuevo intento secesionista, aunque esta vez su estrategia ha incluido, además de la movilización popular y la instrumentalización de las instituciones políticas dependientes del gobierno

2 Carrillo, J. A., «Derechos humanos y derecho internacional», Isegoría, no 22, 2000, p. 72. Acceso web al documento: http://isegoria.revistas.csic.es/index.php/isegoria/article/download/522/522 [consultado: 22/02/2019].

3 BrUni, L., ETA historia politica de una lucha armada, Tafalla, Txalaparta, 1987. 
autonómico, dos nuevos instrumentos orientados a internacionalizar el conflicto: a) una campaña de agitación política y difusión mediática a través de instrumentos de diplomacia pública, canalizados por el Patronat Catalunya MónConsell de Diplomàcia Pública de Catalunya (Diplocat), y b) una amplia ofensiva institucional destinada a dar cobertura a la iniciativa unilateral de secesión en base a la legalidad internacional, habida cuenta de la imposibilidad política de utilizar con éxito la legalidad española para esta finalidad.

En el ámbito interno español, la estrategia independentista catalana contemplaba tres importantes etapas:

$1^{a}$. La convocatoria y celebración de un referéndum en Cataluña, como fundamento de la legitimidad política popular de la decisión unilateral de independencia;

$2^{\mathrm{a}}$. Aprobación en el Parlamento catalán y adhesión de las principales instituciones autonómicas a la Declaración Unilateral de Independencia (DUI) y a la Ley de transitoriedad jurídica y fundación de la República Catalana.

$3^{\mathrm{a}}$. Reconocimiento internacional y apertura de negociaciones con el Estado español para facilitar el proceso de sucesión de estados.

$\mathrm{Si}$ a nivel estatal, la estrategia secesionista con las movilizaciones callejeras pretendía paralizar políticamente al Gobierno y la Administración Central para impedir cualquier respuesta preventiva que abortase la secesión, en el contexto internacional se aspiraba a lograr el apoyo político y el reconocimiento legal del nuevo Estado, siguiendo el modelo generado por la Declaración unilateral de independencia de Kosovo en $2008^{4}$.

Una lectura de la Declaració dels Representants de Catalunya del 10 de octubre de 2017, revela los objetivos internacionales que se pretendían alcanzar con semejante declaración:

«En virtut de tot el que s'acaba d'exposar, nosaltres, representants democràtics del poble de Catalunya, en el lliure exercici del dret d'autodeterminació, i d'acord amb el mandat rebut de la ciutadania de Catalunya,

CONSTITUIM la República catalana, com a Estat independent i sobirà, de dret, democràtic i social.

(...)

4 Un análisis comparado entre la Declaración de la Asamblea kosovar del 17 de febrero de 2008 y la aprobada por el Parlamento de Cataluña el 27 de octubre de 2017 permite constatar las similitudes en el contenido de ambos documentos. Acceso web al documento: https://www. assembly-kosova.org/common/docs/Dek_Pav_e.pdf [consultado: 10/02/2019]. 
POSEM EN CONEIXEMENT de la comunitat internacional i les autoritats de la Unió Europea la constitució de la República catalana i la proposta de negociacions amb l'estat espanyol.

INSTEM a la comunitat internacional i les autoritats de la Unió Europea a intervenir per aturar la violació de drets civils i polítics en curs, i a fer el seguiment del procés negociador amb l'Estat espanyol i serne testimonis.

AFIRMEM que Catalunya té la voluntat inequívoca d'integrar-se tan ràpidament com sigui possible a la comunitat internacional. El nou Estat es compromet a respectar les obligacions internacionals que s'apliquen actualment en el seu territori i a continuar sent part dels tractats internacionals dels quals és part el Regne d'Espanya.

APEL.LEM als Estats i a les organitzacions internacionals a reconèixer la República catalana com Estat independent i sobirà. $>^{5}$

Transcurrido más de un año de esta declaración unilateral de independencia (DUI), resulta evidente el rotundo fracaso de esta estrategia de internacionalización. La nueva República de Cataluña no ha sido reconocida por ningún Estado o institución internacional. Más aún, los intentos de alcanzar un amparo jurídico a su reivindicación secesionista por el Comité de Derechos Humanos de Naciones Unidas o la Corte Europea de Derecho Humanos no han logrado, hasta el momento, ninguna respuesta favorable a sus reclamaciones ${ }^{6}$.

Ello es así porque la fundamentación jurídica internacional que las fuerzas políticas independentistas catalanas han pretendido, $y$ siguen pretendiendo, dar al proceso de secesión unilateral es abiertamente contraria tanto a las normas de derecho positivo como a la práctica desarrollada por los Estados.

Tampoco desde la perspectiva política cabe esperar que las aspiraciones a un nuevo Estado en Cataluña vayan a ser respaldadas por la comunidad inter-

5 Esta Declaración fue firmada el 10 de octubre de 2017 y aprobada por el Parlamento de Cataluña el 27 de octubre de mismo año con 70 votos a favor, 2 votos en blanco, 10 votos en contra y 53 diputados ausentes. El Tribunal Constitucional dictó su inconstitucionalidad el 8 de noviembre del mismo año. Acceso web al documento: https://www.ara.cat/2017/10/10/Declaracio_Independencia_amb_logo_-1.pdf [consultado: 09/02/2019].

6 La solicitud de información remitida al Gobierno español por el Relator Especial sobre la promoción y protección del derecho a la libertad de opinión y expresión puede consultarse en: https://spcommreports.ohchr.org/TMResultsBase/DownLoadPublicCommunicationFil e? $\mathrm{gId}=23698$ [consultado: 10/02/2019]. La información facilitada por el gobierno español al Relator Especial puede encontrarse en: https://spcommreports.ohchr.org/TMResultsBase/ DownLoadFile? gId=34072 [consultado: 10/02/2019]. 
nacional, en particular por las grandes potencias europeas. No existe una razón política, un interés económico o importancia estratégica que justifiquen apoyar desde el exterior la quiebra de la soberanía y la ruptura territorial de un Estado democrático que, además, es la quinta potencia económica y militar en la Unión Europea y una de las principales potencias medias a escala mundial. Esta es una importante diferencia con el caso de Kosovo en su relación con la República de Serbia, que los dirigentes independentistas catalanes han subestimado.

\section{3. ¿DERECHO A LA AUTODETERMINACIÓN O DERECHO A LA SECESIÓN?}

El conflicto político generado por las reclamaciones secesionistas de algunos partidos catalanes, se ha formulado en términos de una pretendida superioridad de la legitimidad política de su aspiración a la independencia, fundamentada en una supuesta voluntad popular de la sociedad catalana sobre la legalidad española, vertebrada a partir del texto constitucional de 1978 y del Estatuto de Autonomía de Cataluña, tras su última reforma de $2010^{7}$.

Más allá de los discursos ideológicos y populistas, el conflicto planteado por el independentismo catalán suscita tres importantes cuestiones que conviene dilucidar para determinar las razones del fracaso de la estrategia de internacionalización: a) ¿según el Derecho Internacional cual es la naturaleza y el alcance del derecho de libre determinación de los pueblos?; b) ¿el ordenamiento jurídico internacional ha establecido unos criterios y unas normas para regular los procesos de secesión? y c) ¿en el conflicto suscitado por el independentismo catalán puede primar la legitimidad política alegada sobre la legalidad internacional o las normas jurídicas nacionales?

Comencemos por dejar constancia de dos importantes evidencias: a) la realidad política y jurídica de la Comunidad Autónoma de Cataluña y de sus ciudadanos, no responde a las circunstancias de un pueblo sometido a una dominación colonial ni tampoco a las de un territorio no autónomo; b) el pueblo catalán ha podido ejercer el derecho a expresar su libre voluntad política (autodeterminación) respecto de la Constitución de 1978 y del Estatuto de Autonomía.

A la luz de ambos hechos cabe plantearse si el derecho a la autodeterminación del pueblo catalán encuentra su fundamento en la legalidad internacional o si por el contrario la base jurídica para su reconocimiento y ejercicio

7 Ley Orgánica 6/2006 de 19 de julio de 2006. Boletín Oficial del Estado, nº 172 del 20/07/2006. 
debe sustentarse en el ordenamiento interno español. Para dar respuesta a esta cuestión, debemos analizar los orígenes, evolución y aplicación de la libre determinación de los pueblos como principio jurídico y como derecho.

Es bien conocido que en su formulación inicial «la igualdad de derechos y la libre determinación de los pueblos» se estableció como un principio jurídico básico del orden internacional, recogidos en los arts. 1 y 55 de la Carta de las Naciones Unidas. Sin embargo, en su aplicación la libre determinación de los pueblos quedó inicialmente limitado a los pueblos sometidos a un régimen colonial, identificándose con los procesos que garantizasen su decisión política, al margen de la voluntad de las potencias colonizadoras, como condición necesaria para su pleno desarrollo político, económico y social. La resolución A/RES/1514 (XV) del 14 de diciembre de 1960 confirmaba esta aplicación restrictiva a las situaciones coloniales ${ }^{8}$. No obstante y desde el primer momento, este principio se vio sometido a la limitación impuesta por otro principio recogido en el art. 2.4 de la Carta, referido a la integridad territorial y la independencia política de los Estados. En otras palabras, la libre determinación de los pueblos no podía ser interpretada como fundamento para procesos de secesión de pueblos no colonizados. El punto 6 de la Resolución lo especificaba de un modo inequívoco: «Todo intento encaminado a quebrantar total o parcialmente la unidad nacional y la integridad territorial de un país es incompatible con los propósitos y principios de la Carta de las Naciones Unidas»

A su vez, la Resolución A/RES/1541 (XV) del 15 de diciembre de 1960, concretaba las formas de aplicación de este principio a los territorios no autónomos regulados en los arts. 73 y ss. de la Carta9. Básicamente el Principio VI establecía tres posibles resultados: a) la creación de un Estado independiente y soberano; b) la libre asociación con un Estado independiente, y c) la integración en un Estado independiente ${ }^{10}$. Sin embargo no especificaba una regulación jurídica particular a la que debieran adecuarse los procesos necesarios

8 Declaración sobre la concesión de la independencia a los países y pueblos coloniales. A/RES/1514 (XV) del 14 de diciembre de 1960. Acceso web al documento: http://www.un.org/es/comun/ docs/?symbol=A/RES/1514(XV) [consultado: 08/02/2019].

9 Principios que deben servir de guía a los Estados miembros para determinar si existe o no la obligación de transmitir la información que se pide en el inciso e) del artículo 73 de la Carta. A/RES/1541 (XV) del 15 de diciembre de 1960. Acceso web al documento: http://undocs.org/es/A/RES/1541(XV) [consultado: 08/02/2019].

10 Casos de asociación con la potencia colonizadora lo encontramos entre los miembros de la Commonwealth británica, como Canadá. Entre los ejemplos de integración en la potencia colonizadora se encuentra los territorios y provincias de ultramar francesas. 
para alcanzar tales resultados, dejando así para los ordenamientos internos o la práctica internacional las formas concretas de actuación de los pueblos colonizados para su autodeterminación.

Más tarde, la Asamblea General, en la Resolución A/RES/2625 (XXV) de 1970 sobre la Declaración de los principios del Derecho Internacional, volvió a incluir «la igualdad de derechos y la libre determinación de los pueblos» esta vez como un principio básico del derecho internacional aplicable a las relaciones entre todos los Estados y abierto a «cualquier otra condición política libremente decidida por un pueblo». Con ello abría la aplicación del principio a otras decisiones políticas diferentes de las contempladas por la Resolución 1514, como la determinación del régimen político, la reunificación de Estados o la secesión.

Sin embargo siguió manteniendo las restricciones impuestas a este principio por la aplicación de los principios de integridad territorial y no injerencia en los asuntos internos de todo Estado soberano e independiente «que se conduzca de conformidad con el principio de la igualdad de derechos y de la libre determinación de los pueblos antes descrito y estén, por tanto, dotados de un gobierno que represente a la totalidad del pueblo perteneciente al territorio, sin distinción por motivos de raza, credo o color» ${ }^{11}$.

Por tanto, atendiendo a los documentos fundamentales del denominado derecho de la descolonización, el principio de la libre determinación de los pueblos no podía aplicarse de una forma expansiva hasta el punto de amparar procesos secesionistas unilaterales o conquistas territoriales que afectasen directamente a la soberanía y la integridad territorial de los Estados.

En 1966 los Pactos Internacionales de Derechos Civiles y Políticos y de Derechos Económicos, Sociales y Culturales recogieron en sus respectivos arts. 1 la libre determinación de los pueblos formulada como un derecho fundamental de naturaleza y ejercicio colectivos. Para ello utilizaron la misma fórmula en ambos tratados:

«1.- Todos los pueblos tienen el derecho de libre determinación. En virtud de este derecho establecen libremente su condición política y proveen asimismo a su desarrollo económico, social y cultural.

(...)

11 A/RES/2625 (XXV) Declaración sobre los principios del derecho internacional referentes a las relaciones de amistad y a la cooperación entre los Estados de conformidad con la Carta de las Naciones Unidas, del 24 de octubre de 1970. Acceso web: http://undocs.org/es/A/RES/2625(XXV) [consultado: 08/02/2019]. 
3.- Los Estados Partes en el presente Pacto, incluso los que tienen la responsabilidad de administrar territorios no autónomos y territorios en fideicomiso, promoverán el ejercicio del derecho de libre determinación, y respetarán este derecho de conformidad con las disposiciones de la Carta de las Naciones Unidas.»

En tanto que derecho fundamental, su aplicación no podía quedar circunscrita a los pueblos colonizados o a los territorios no autónomos, máxime si tenemos en cuenta que el 23 de marzo de 1976, fecha de entrada en vigor de los Pactos, el proceso descolonizador había prácticamente concluido.

Por otra parte resultaba novedoso que se incluyese un derecho de titularidad y ejercicio colectivos en unos tratados que regulaban derechos individuales. Tanto la doctrina como la práctica internacional han interpretado que el reconocimiento de este derecho colectivo tenía como finalidad garantizar el ejercicio de ciertos derechos individuales en el ámbito interno de los estados, como por ej. el derecho de reunión pacífica (art. 21); el de asociación (art. 22) o el de sufragio activo y pasivo (art. 25) ${ }^{12}$.

Más aún, la regulación y protección de los derechos humanos queda atribuida de forma directa al ordenamiento jurídico interno de los Estados (art. 2 de los Pactos) que debe adecuarse al contenido de los tratados internacionales. Conviene, no obstante, señalar que el conjunto de los derechos humanos fundamentales no puede considerarse políticamente, ni interpretarse jurídicamente, una categoría de derechos anclados en un orden jurídico natural trascendente, sino como el resultado de la evolución del orden jurídico internacional de carácter positivo. Por consiguiente, admite restricciones en su aplicación derivadas bien de la concurrencia en el ejercicio de varios derechos fundamentales o bien por la necesaria salvaguardia de los principios que fundamentan el orden común de convivencia, nacional o internacional, sin el cual tales derechos no tendrían vigencia ni podrían ser garantizados. Así se desprende de lo dispuesto en el art. 4 de los Pactos.

En efecto, si la regulación, garantía y protección real de los derechos humanos es una responsabilidad prima facie de los estados en el ejercicio de su soberanía, ésta no se ejerce de un modo aislado sino en el inevitable contexto de sus relaciones con los demás estados de la comunidad internacional. Es por ello

12 Mariño, F.M., «Derechos colectivos y ordenamiento jurídico internacional», en ANSUÁTEGUI, F.J. (ed.), Una discusión sobre los derechos colectivos, 2001, pp. 77-94. 
que los estados no pueden eludir la obligación de regular y proteger los derechos humanos ni tampoco la responsabilidad derivada de su violación, alegando que se trata de un asunto interno sujeto a sus competencias soberanas ${ }^{13}$.

Es precisamente debido a la necesaria complementariedad entre ambos sistemas jurídicos, el nacional y el internacional, por lo que cualquier interpretación o aplicación excluyente de alguno de ellos resulta incompleta, poco eficaz y, a la larga, provoca una degradación paulatina del propio sistema internacional.

Esta consideración sobre el carácter positivo de los derechos regulados en los Pactos internacionales, incluido el de la libre determinación, se opone claramente a los argumentos más extremos formulados por los dirigentes independentistas que los consideran un protoderecho inherente a la voluntad popular y cuyo ejercicio corresponde en exclusividad al pueblo de Cataluña, sin que pueda contraponerse norma jurídica, nacional o internacional, que lo limite en su ejercicio ${ }^{14}$.

Una versión más sutilmente argumentada, aunque igualmente radical en el fondo, es la que sostienen algunos autores que alegando la naturaleza de «ius cogens» y por tanto imperativa «erga omnes» de los derechos humanos, deducen la primacía y aplicabilidad directa del derecho a la libre determinación sobre las normas del ordenamiento interno que lo regulan y limitan en su ejercicio pues, según su argumentación, en caso contrario no podrían hacerse efectivos otros derechos humanos fundamentales ${ }^{15}$.

13 Como ejemplo de la responsabilidad penal derivada de graves violaciones de derechos humanos bastará con citar el art. 5 del Estatuto de la Corte Penal Internacional. Respecto de las consecuencias de la ignorancia o violación de principios fundamentales del derecho internacional véase la sentencia de la Corte Internacional de Justicia, en el Asunto de las actividades militares y paramilitares en Nicaragua. Militarv and Paramilitary Activities in und against Nicaragua. (Nicaragua v. United States of America). Merits, Fudgment. I.C.F. Reports 1986, p. 14. Acceso web al documento: https://www. icj-cij.org/files/case-related/70/070-19860627-JUD-01-00-EN.pdf [consultado: 09/02/2019].

14 Entrevista de Carlos Alsina al Presidente de la Generalidad Quim Torra el 13 de febrero de 2019. Acceso al documento: https://twitter.com/OndaCero_es/status/1095612731292610562

15 Esta es la argumentación utilizada en la declaración Unilateral de Independencia cuando afirma: «La justícia i els drets bumans individuals i col-lectius intrínsecs, fonaments irrenunciables que donen sentit a la legitimitat històrica i a la tradició jurídica i institucional de Catalunya, són la base de la constitució de la República catalana.

(...)

Davant la constatació que les institucions de l'Estat han rebutjat tota negociació, han violentat el principi de democràcia i autonomia, i han ignorat els mecanismes legals disponibles a la Constitució, la Generalitat de Catalunya ba convocat un referèndum per a l'exercici del dret a l'autodeterminació reconegut en el dret internacional.» 
Esta es la posición de Ezeizabarrena cuando señala:

«En este sentido, el ejercicio de los derechos citados no puede llevarse a cabo en el contexto español y en otros con las debidas garantías ni con la eficacia que dice garantizar el ordenamiento jurídico. ¿Nos encontramos ante agresiones sistemáticas o ante hechos puntuales? La respuesta no es sencilla. De una u otra manera, el derecho de libre determinación vinculado con la protección de los Derechos Humanos adquiere un carácter más sustantivo frente a la mera reclamación de una soberanía territorial que, según algunas tesis, puede chocar en el Derecho Internacional con el principio de intangibilidad de las fronteras» ${ }^{16}$.

Como puede apreciarse, la razón última para afirmar la prevalencia del derecho a la libre determinación sobre el principio de integridad territorial es su conversión en la única garantía para la protección efectiva del resto de derechos humanos. Es la denominada por la Corte Internacional de Justicia como «remedial secession». ${ }^{17}$ Naturalmente, para recurrir a esta argumentación hay que afirmar, en contra de la más elemental evidencia, que el Estado español carece de un sistema de garantías jurídicas que protejan efectivamente los derechos civiles y políticos fundamentales.

Planteado el debate doctrinal en estos términos, cabe preguntarse si la formulación inicial del principio de igualdad de derechos y libre determinación de los pueblos, así como su posterior traducción en un derecho fundamental, ha tenido un desarrollo jurídico internacional y/o una aplicación que permitan considerar que las limitaciones introducidas en las mencionadas re-

16 EzeizabarRena, X., «Derecho de libre determinación y derecho a decidir: nueva soberanía y derechos humanos en el siglo XXI», Cuadernos Deusto de Derechos Humanos, nº 90, 2017, p. 21.

Gros Espiell, H., «En torno al derecho a la libre determinación de los pueblos», Anuario de Derecho Internacional, vol. III, 1976; pp. 49-74.

17 Opinión consultiva de la Corte Internacional de Justicia sobre la declaración unilateral de independencia de Kosovo. Accordance with International Law of Unilateral Declaration of Independence in respect of Kosovo, Advisory Opinion; IC7 Reports 2010; párrafo 82; p. 403. Acceso web al documento: https://www.icj-cij.org/files/case-related/141/141-20100722-ADV-01-00-EN.pdf [consultado: 22/02/2019].

JIMÉNEZ, C., «Los principios de soberanía e integridad territorial y de autodeterminación de los pueblos en la Opinión consultiva sobre Kosovo: una oportunidad perdida», Revista Española de Derecho Internacional, LXIII, 1, 2011, pp. 29-54.

ANDRES, P., «Tu quoque, Corte? La banalización de los poderes del CdS en la Opinión consultiva sobre la conformidad con el Derecho internacional de la declaración unilateral de independencia relativa a Kosovo», Revista Española de Derecho Internacional, LXIII, 1, 2011, pp. 55-78. 
soluciones y en los Pactos Internacionales, han quedado derogadas o sustancialmente modificadas hasta el punto de amparar, en la práctica, las secesiones unilaterales de territorios y poblaciones pertenecientes a un Estado independiente que cumple con los estándares internacionales de democracia y respeto de los derechos humanos, como es el caso de España ${ }^{18}$.

Esta cuestión ha adquirido relevancia política y jurídica a raíz de los cambios estatales y territoriales que se han producido en la sociedad internacional tras el fin de la bipolaridad. A las desintegraciones de la Unión Soviética; la antigua Yugoslavia y la República Checoslovaca, se agregó la reunificación alemana. Todos estos cambios estatales modificaron sustancialmente el mapa geopolítico europeo ${ }^{19}$.

En cuanto al ejercicio del derecho de autodeterminación en el ámbito interno del Estado, incluyendo la opción secesionista, el Derecho Internacional no establece unas normas específicas que lo regulen ya que corresponde determinarlo a la esfera jurídica doméstica de los Estados. No obstante, el Derecho Internacional sí establece una serie de principios y normas jurídicas que en su conjunto fijan un marco legal dentro del cual debe llevarse a cabo esta regulación interna. Entre estos principios se encuentran: a) la integridad territorial de los Estados, b) la no injerencia en los asuntos internos; c) la prohibición del uso de la fuerza, y d) el respeto de los derechos humanos fundamentales, incluidos los derechos de las minorías.

La consideración conjunta de tales principios impide el recurso a determinados procedimientos para llevar a cabo el ejercicio del derecho de li-

18 A las declaraciones de los dirigentes políticos independentistas catalanes y vascos sobre las violaciones sistemáticas del Estado español de derechos fundamentales, hay que oponer la evidencia de que España no ha sido objeto del procedimiento contemplado actualmente en el art. 7 del Tratado de la Unión Europea, como sí lo han sido otros Estados miembros como Austria (1999), Polonia (2017) o Hungría (2018). Por otra parte, el recurso individual a la Corte Europea de Derechos Humanos constituye una garantía judicial adicional de los derechos humanos que no sólo no es ajena al ordenamiento interno sino que su eficacia deriva de su incorporación al mismo.

MANGas Martín, A.; «La secesión de territorios en un Estado miembro: efectos en el derecho de la Unión Europea», Revista de Derecho de la Unión Europea, nº 25, julio-diciembre 2013, pp. 47-68. Acceso web al texto: http://www.pensamientocritico.org/araman0917.pdf [consultado: $14 / 02 / 2019]$.

19 Pons Rafols, X., Cataluña: Derecho a decidir y Derecho Internacional, Madrid, Reus, 2015.

Soroeta, J., «El derecho a la libre determinación de los pueblos en el siglo XXI: entre la realidad y el deseo», Cursos de Derecho Internacional y Relaciones Internacionales de Vitoria-Gasteiz, 2011, pp. 451-502. Acceso web al texto: https://www.ehu.eus/documents/10067636/10765866/2011JuanFrancisco-Soroeta-Liceras.pdf/00f0923b-31b8-0f20-b596-f60a02f77733 [consultado: 14/02/2019]. 
bre determinación de los pueblos por contrariar abiertamente las normas y la práctica internacional. Por ejemplo, excluye el recurso a las distintas formas de violencia ilegal, como el terrorismo, los golpes de Estado, las rebeliones militares o las agresiones u ocupaciones externas, ya que se trata de situaciones en las que no concurren las condiciones mínimas para el ejercicio pleno de este derecho.

Pero también descarta aquellos procesos que sin recurrir a la violencia implican cambios territoriales unilaterales, provocan una grave violación de derechos humanos fundamentales o rechazan asumir las obligaciones internacionales derivadas de la sucesión de $\operatorname{Estados}^{20}$. Desde esta perspectiva, el recurso a la secesión unilateral como «el único remedio» para poner fin a aquellas situaciones en las que el Estado provoca una sistemática y grave violación de derechos humanos fundamentales, constituye una forzada interpretación tanto del principio como del derecho a la libre determinación de los pueblos.

Existe una práctica internacional que de un modo claro confirma una opinio iuris consolidada contraria a esta opción. Ello es debido a la existencia legal de un sistema de sanciones internacionales, incluido el recurso a la intervención colectiva si así se decide por el Consejo de Seguridad (responsabilidad de proteger), que permite resolver estas situaciones de violación de derechos humanos respetando la integridad territorial de los Estados. El caso de las sanciones contra el régimen del apartheid en Sudáfrica demuestra la posibilidad y eficacia de esta opción.

Teniendo presente estas consideraciones, para que el proceso de secesión de un Estado sea compatible con el marco general establecido por el Derecho Internacional deben cumplirse tres importantes condiciones: a) que la secesión sea el resultado del ejercicio del derecho a la libre determinación tal y como se encuentra regulado por el orden jurídico interno del Estado; b) que el ejercicio del derecho a la libre determinación no se realice en abierta violación de principios básicos del orden jurídico internacional, y c) que el nuevo Estado cumpla los requerimientos establecidos por el Derecho Internacional para el pleno ejercicio de su soberanía (reconocimiento por los demás Estados, respeto de los derechos y obligaciones internacionales asumidos por el Estado originario frente a terceros, etc.).

20 Blanc, A., La herencia soviética. La Comunidad de Estados Independientes y los problemas sucesorios, Madrid, Tecnos, 2004. 


\section{EL EJERCICIO DEL «SUPUESTO» DERECHO A LA SECESIÓN UNILATERAL de CaTAluña: obstáculos JuRÍDicos y POLÍTICOS}

Cuando aplicamos estas consideraciones jurídicas a los sucesos acaecidos en Cataluña durante 2017, observamos que los dirigentes políticos de las principales instituciones autonómicas desarrollaron su estrategia independentista ignorando o subestimando las importantes obligaciones jurídicas y exigencias políticas que debían asumir a lo largo de todo el proceso de secesión.

Crearon y difundieron mediáticamente, tanto nacional como internacionalmente, un discurso demagógico cuya finalidad era legitimar un referéndum que se sabía que era ilegal pero cuya represión, por parte de las autoridades españolas, justificaría el reconocimiento de terceros países o de instituciones internacionales en aras de proteger los derechos de los ciudadanos de los catalanes. Ello facilitaría la inevitable negociación con el Estado español para hacer viable la nueva República de Cataluña, al situarla en una posición negociadora dominante $\mathrm{o}$, al menos, incuestionable.

Desde la perspectiva jurídica se afirmaba que puesto que el Estado español había ratificado los Pactos Internacionales de Derechos Humanos en 1977 y, por tanto, desde esa fecha había asumido el derecho a la libre determinación de los pueblos como parte de su ordenamiento jurídico, no podía ignorar la reclamación catalana de ejercerlo sin violarlo ${ }^{21}$. Sin embargo se obviaba que su regulación en el ámbito interno, como para el resto de los derechos humanos, se realizó primariamente por la Constitución de 1978 precisamente en el ejercicio de la libre determinación del pueblo español, incluida la ciudadanía catalana, expresada en el referéndum que la aprobó. Por ello invocar el derecho de libre determinación del pueblo catalán disociándolo de la legislación que lo reconoce, regula y ampara no sólo es un error jurídico es también una deliberada e injustificable manipulación de los hechos ${ }^{22}$.

En efecto, aunque la Constitución no recoge una formulación explícita de la libre determinación como uno de los derechos regulados en el Título I, sí establece un procedimiento para ejercerlo mediante referéndum en el art. 92. Su redacción hace alusión a «las decisiones politicas de especial trascendencia»y,

21 España se incorporó como parte de ambos tratados mediante ratificación el 13 de abril de 1977. BOE n ${ }^{\circ} 103$ del 30 de abril de 1977. Acceso web al documento: https://www.boe.es/buscar/doc.php?id=BOE-A-1977-10733 [consultado: 08/02/2019].

22 Conviene recordar el art. 1 de la Constitución que expresamente reconoce que la soberanía nacional reside en el pueblo español. 
desde luego, la propuesta de independencia de una parte del territorio y la población del Estado español entraría de lleno en esa categoría. La naturaleza jurídicamente «consultiva» del referéndum no impediría que su resultado fuese políticamente vinculante. Sin embargo, la conexión de este artículo con el artículo 1 obliga a considerar que la realización de un referéndum sobre la secesión de una región o comunidad autónoma, no podría quedar restringida a ella sin que ello afectase al derecho a la libre determinación del resto de los ciudadanos españoles, ya que la decisión política final afectaría a la soberanía nacional y por consiguiente a todos los españoles.

Que exista esta limitación no permite afirmar que la Constitución española impide el derecho de autodeterminación de Cataluña, sólo que lo condiciona a un ejercicio conjunto con el resto de ciudadanos del Estado y, desde luego, la Constitución y la legislación autonómica no imponen al Estado una obligación de celebrar o reconocer el resultado de un referéndum sobre la secesión, solicitado o convocado por las autoridades de una comunidad o ciudad autónoma, al margen de los procedimientos constitucionales.

Para que semejante obligación fuese exigible sería necesario un cambio de la actual Constitución que abriese la posibilidad legal de un referéndum que realizándose por una parte de la población española, pudiese modificar la configuración territorial y la soberanía del Estado. Sobre esta problemática constitucional, el Derecho Internacional no tiene nada que decir, ya que pertenece al ámbito jurídico doméstico, salvo que la nueva redacción constitucional debería adecuarse al marco general de principios jurídicos internacionales que hemos mencionado.

A este respecto, el pronunciamiento de la Corte Suprema de Canadá en su sentencia del 20 de agosto de 1998 sobre el derecho de libre determinación de Quebec, citado con frecuencia por la doctrina independentista, resulta suficientemente claro:

«The Court in this Reference is required to consider whether Quebec has a right to unilateral secession.

(...)

Quebec could not, despite a clear referendum result, purport to invoke a right of self-determination to dictate the terms of a proposed secession to the other parties to the federation. The democratic vote, by however strong a majority, would have no legal effect on its own and could not push aside the principles of federalism and the rule of law, the rights of individuals and minorities, or the operation of democracy in the other provinces or in Canada as a whole. Democratic rights under the Constitution cannot be 
divorced from constitutional obligations. Nor, however, can the reverse proposition be accepted: the continued existence and operation of the Canadian constitutional order could not be indifferent to a clear expression of a clear majority of Quebecers that they no longer wish to remain in Canada. The other provinces and the federal government would have no basis to deny the right of the government of Quebec to pursue secession should a clear majority of the people of Quebec choose that goal, so long as in doing so, Quebec respects the rights of others. The negotiations that followed such a vote would address the potential act of secession as well as its possible terms should in fact secession proceed. There would be no conclusions predetermined by law on any issue. Negotiations would need to address the interests of the other provinces, the federal government and Quebec and indeed the rights of all Canadians both within and outside Quebec, and specifically the rights of minorities. $\gg^{23}$

En otras palabras, en el caso de Quebec la Corte Suprema canadiense rechazó la secesión unilateral y sólo admitió un proceso de independencia negociada siempre y cuando hubiese alcanzado «a clear referendum result». No obstante y desde el punto de vista internacional, este caso resulta jurídica y políticamente irrelevante como posible precedente para la situación en Cataluña por varias razones.

En primer lugar esta sentencia no tiene valor legal, ni tan siquiera como interpretación del derecho internacional a la libre determinación de los pueblos, fuera del ámbito jurisdiccional de la Corte Suprema que, obviamente, queda restringido a Canadá. En segundo término, porque la organización estatal canadiense, como Estado independiente en el seno de la Commonwealth británica, es claramente distinta del modelo de organización autonómico adoptado por el Estado español. Ambos aspectos, alcance jurídico de la sentencia y organización política del Estado, son con frecuencia ignorados por quienes invocan el precedente de Quebec.

En cuanto a España, la otra posibilidad para ejercer la libre determinación mediante referéndum, es lograr que el Gobierno, las Cortes y el Rey acepten ejercer las competencias que les atribuye la Constitución para llevarlo a cabo, es decir proponer, aprobar y convocar respectivamente. Esta fue la opción que adoptó el lehendakari Ibarretxe, con el apoyo de una mayoría del

23 Reference re Secession of Quebec, [1998] 2 SCR 217, 1998 CanLII 793 (SCC). Acceso web al documento: http://canlii.ca/t/1fqr3 [consultado: 23/02/2019]. 
Parlamento Vasco, para su propuesta secesionista en 2003. El debate y votación de esta iniciativa en el Congreso de los Diputados en 2005 se saldó con 313 votos en contra y 29 votos a favor, poniendo fin a este proceso.

Naturalmente los dirigentes independentistas catalanes eran perfectamente conscientes de que ambas fórmulas, cambio constitucional o aprobación legal del referéndum de autodeterminación con fines secesionistas, eran inviables a corto o medio plazo. Por tanto trataron de forzar una vía política alternativa, siguiendo el modelo kosovar, con la expectativa de que diese resultado ${ }^{24}$.

Es en ese contexto donde adquiere toda su relevancia el obstáculo político, ya que mientras el referéndum involucre al pueblo español y no al pueblo vasco o catalán, resulta evidente que éstos últimos no alcanzarían la mayoría suficiente para fundamentar su independencia o para lograr un cambio constitucional. La cuestión de la invocación política del «principio democrático» para avalar el ejercicio de la libre determinación, todavía se dificulta más cuando se analizan los resultados de las convocatorias electorales autonómicas, procesos que también constituyen un ejercicio del derecho de autodeterminación en el ámbito interno, pues determinan los titulares del ejercicio de los poderes legislativo y ejecutivo, tanto nacional como autonómico, durante toda una legislatura.

En el caso de Cataluña, los resultados de las dos últimas elecciones autonómicas de 2015 y 2017 son reveladores. Sobre el censo total de votantes se produjo una abstención del 25,05\% y del 20,91\% respectivamente. Sobre los votantes efectivos, los partidos que reclaman la celebración de un referéndum de autodeterminación alcanzaron un 51,04\% (equivalente al 43,8\% del censo total) en 2015 y un 54,96\% (equivalente al 43,3\% del censo total) en 2017. Estos resultados electorales son a su vez distorsionados en la representación parlamentaria por la aplicación de la ley D’Hont. Ambas elecciones concedie-

24 Tras el fracaso de la iniciativa secesionista, se está difundiendo una narrativa oficial según la cual los actos políticos e institucionales adoptados en Cataluña en los últimos meses de 2017 sólo buscaban forzar una negociación política con el Gobierno del Estado español. Semejante planteamiento implica necesariamente o bien que los dirigentes catalanes nunca creyeron que la celebración del referéndum y la DUI permitirían alcanzar la creación de la República Catalana, en cuyo caso mintieron deliberadamente a miles de ciudadanos catalanes a los que representaban, o bien creyeron sinceramente que podrían alcanzar la independencia con éxito, en cuyo caso demostraron un preocupante grado de ignorancia política e incompetencia funcional gravemente lesivo para las instituciones que representaban y los intereses ciudadanos que estaban obligados a proteger. 
ron a los partidos independentistas unas mayorías de 83 escaños, sobre 135, en 2015 y 78 en las de 2017.

Parece evidente, salvo para los dirigentes independentistas, que en términos reales no existe una posición mayoritaria suficiente entre la ciudadanía catalana para albergar una sólida expectativa de que un referéndum, incluso si quedase restringido a Cataluña, pudiese fundamentar un proceso de secesión. En semejantes circunstancias es razonable que el Gobierno español rechace negociar la celebración de dicho referéndum dado el coste político y jurídico que ello supondría.

La invocación de unas mayorías en el Parlamento de Cataluña, por otro lado menguantes, para realizar una DUI con la esperanza de que el Estado español o terceros países la reconociesen como legal y políticamente legítima, se reveló un proyecto quimérico y condenado al fracaso, como efectivamente ocurrió.

\section{EL FRACASO DE LA ESTRATEGIA INTERNACIONAL DEL GOBIERNO INDEPENDENTISTA CATALÁN}

La ausencia de una legalidad nacional e internacional junto con el déficit de legitimidad democrática, características decisivas que concurrían en el proceso secesionista iniciado por el Govern de Cataluña, presidido por Carles Puigdemont, difícilmente podían ser compensadas por la estrategia política de internacionalización de dicho proceso. Esta estrategia descansaba en tres instrumentos fundamentales: a) una intensiva campaña mediática; b) una activa diplomacia pública de las instituciones autonómicas y de los líderes independentistas, y c) una importante financiación pública y privada.

Respecto de la campaña mediática, a nivel nacional se utilizaron distintos medios tradicionales de comunicación de masas, tanto públicos (TV3; Catalunya Ràdio), como privados (El Periódico; El Punt Avui o La Vanguardia). Pero sobre todo, se recurrió al empleo de medios digitales por su capacidad de difusión transnacional (El Nacional.cat; Ara.cat; Naciodigital.cat; Elpuntavui.cat, o Elperiodico.com).

El principal instrumento para garantizar la campaña de propaganda en los medios de comunicación públicos se articulaba mediante el control institucional que ejercía y que se sigue ejerciendo por el Consejo Audiovisual de Cataluña sobre la Corporación Catalana de Medios Audiovisuales S.A., de la que dependen 6 canales de televisión, 4 emisoras de radio y una que emite por 
Internet, y la Agencia Catalana de Noticias ${ }^{25}$. Respecto de los medios de comunicación privados, se utilizó preferentemente la financiación a través de dos importantes instrumentos: a) las subvenciones públicas, estimadas en 2016 en 7,37 millones de euros, y b) la publicidad institucional por una cuantía de 30,7 millones de euros.

En cuanto a los medios de comunicación internacionales, la Agencia $\mathrm{Ca}$ talana de Noticias creó la Catalan News para proveer de noticias sobre Cataluña a los corresponsales extranjeros establecidos en Barcelona ${ }^{26}$. Con objeto de disponer un mejor acceso a la actividad informativa de estos corresponsales extranjeros se abrió el International Press Centre of Barcelona, cerrado en 2011. Más tarde, para facilitar la cobertura informativa por los medios internacionales del referéndum ilegal del 1 de octubre de 2017, el holding multimedia Mediapro habilitó temporalmente el International Press and Broadcasting Center.

Desde la perspectiva de las instituciones catalanas y los dirigentes independentistas, el objetivo de esta movilización mediática, con los correspondientes recursos financieros, era claramente dominar la narrativa, en Cataluña y en Europa, sobre el proceso de secesión. Sin embargo, en la medida en que ciertos medios de comunicación, nacionales e internacionales, comenzaron a discrepar en sus noticias de esta narrativa oficial, se inició una campaña de presión y acoso sobre sus corresponsales que terminó siendo objeto de un informe de la organización no gubernamental Reporteros sin Fronteras difundido en 2018 con el título: «Reporteros sin Fronteras pide respeto al libre ejercicio del periodismo en Cataluña» en el que se afirmaba:

«Junto al ciberacoso en redes sociales, que los políticos independentistas y responsables de prensa 'den toques', 'corrijan' o muestren excesivo interés en lo que se publica fuera sobre Cataluña es una de las principales quejas que esgrimen los corresponsales.»

25 De acuerdo con los datos del Presupuesto de 2017, ya que los de 2018 y 2019 son presupuestos prorrogados, los gastos asignados al Consell Audiovisual de Catalunya eran de 5,3 millones de euros. Presupostos 2017. Mientras que la partida 533 Medios de Comunicación Social ascendió a 309,5 millones de euros de los que 289,9 millones fueron destinados a la Corporación Catalana de Medios Audiovisuales S.A. Acceso web al documento: http://aplicacions.economia.gencat.cat/ wpres/2017/05_navega_pressupost.htm [consultado: 23/02/2019].

26 Según se indica en la página web oficial «Catalan News aim is meeting the international public's need for accurate, first-hand information from and about Catalonia, especially in areas where access to information is more difficult for foreign media. We provide text and audiovisual content tailored to the needs of our international audience.». Acceso web al document: http://www.catalannews.com/about-us [consultado: 23/02/2019]. 
Y sobre la presión institucional de las autoridades catalanas independentistas agrega:

«Reporteros Sin Fronteras ha podido comprobar este extremo y da fe de su veracidad.

(...)

RSF considera que categorizar a los periodistas por afinidades políticas y realizar listas de afecciones y desafecciones a una causa es más propio de regímenes totalitarios que de sistemas democráticos. $\gg^{27}$

Si nos centramos ahora en la utilización de la diplomacia pública para lograr el apoyo exterior de organizaciones, partidos políticos, gobiernos e, incluso, las instituciones de la Unión Europea, el principal instrumento utilizado fue la red internacional de oficinas que, bajo la cobertura de la representación institucional de Cataluña o la difusión de la cultura catalana, desempeñaban una eficaz actividad de lobby en favor del proceso secesionista.

Según la información en la página web oficial del Departamento de Acción Exterior, Relaciones Institucionales y Transparencia, el Gobierno de Cataluña canalizó su proyección internacional a través de una red de setenta oficinas, entre delegaciones del Gobierno y oficinas sectoriales ${ }^{28}$.

La conocida como DiploCat, acrónimo del Consejo de Diplomacia Pública de Cataluña, se constituyó en 2012 y estuvo activa hasta su cierre en 2017 como consecuencia de la aplicación del art. 155 de la Constitución. A mediados de 2018 el nuevo Presidente de la Generalitat, Quim Torra, con el respaldo del Parlamento de Cataluña, aprobó la creación de la Consejería de Asuntos Exteriores de la que depende el Departamento de Acción Exterior, Relaciones Institucionales y Transparencia que ha vuelto a establecer delegaciones gubernamentales en cinco países (Francia; Italia; Alemania; Reino Unido y Estados Unidos) así como ante la Unión Europea.

Para esta proyección internacional, el Departamento de Acción Exterior dispuso en 2017 de un presupuesto de 18, 2 millones de euros. En los presupuestos de 2019 la Secretaría de Acción Exterior y Unión Europea tiene asignada una cuantía

27 Reporteros sin Fronteras. Informe \#Respect Press Cat. Reporteros sin Fronteras pide respeto al libre ejercicio del periodismo en Cataluña. 13/10/2017. Acceso web al documento: https://rsf-es. org/_files/200005680-6ff5470eed/2017_RSF_inf_respectpresscat_act.13.10.17.pdf; pp. 7 y 9 [consultado: 23/02/2019].

28 Acceso web: http://exteriors.gencat.cat/es/departament/representacio-a-lexterior/ [consultado: 23/02/2019]. 
de 36,7 millones de euros ${ }^{29}$. Sin embargo, esta movilización de recursos económicos no tuvo su correspondencia en los resultados internacionales esperados.

Uno de los objetivos prioritarios de la acción exterior del gobierno catalán era lograr que la Comisión y el Parlamento Europeos mantuviesen una posición favorable o, al menos, neutral respecto del proceso secesionista. Ello, teniendo en cuenta que el Estado español es un país miembro de la Unión Europea, se consideraba un éxito político y un factor debilitador de la capacidad de reacción del Gobierno ante las iniciativas independentistas.

La constante afirmación de la vocación europeísta de la futura República Catalana, incluida también en la DUI, buscaba compensar en el contexto europeo el déficit de apoyo político en España y, en último extremo, facilitar una posible mediación comunitaria en la negociación final con el Estado español. Tales aspiraciones nunca se lograron.

Desde el primer momento la Comisión Europea mantuvo una posición institucional de no injerencia en un asunto que siempre consideró exclusivo de la política interna española. No obstante, en varias ocasiones tuvo que realizar declaraciones oficiales para desmentir las recurrentes manifestaciones de dirigentes catalanes sobre la continuidad del nuevo Estado como miembro de la Unión Europea. Especial importancia tuvo la declaración de la Comisión del 2 de octubre de 2017 en la que expresamente calificó de ilegal la votación realizada el día anterior ${ }^{30}$.

La negativa de los gobiernos de las principales potencias, Estados Unidos; Rusia; Francia; Alemania o el Reino Unido ${ }^{31}$, a aceptar la legalidad del re-

29 Generalitat de Catalunya. Departamet de la Vicepresidència D’Economia i Hisenda. Pròrroga. Presupostos de la Generalitat de Catalunya 2019, p. 41. Acceso web al documento: http:// economia.gencat.cat/web/.content/70_pressupostos/fitxers/elaboracio-2019/prorroga/estatdespeses.pdf [consultado: 23/02/2019].

30 European Commission. Statement on the Events in Catalonia, 2 de octubre de 2017. Acceso web al documento: http://europa.eu/rapid/press-release_STATEMENT-17-3626_en.htm [consultado: 23/02/2019].

31 Prime MinISTER's OfFiCE, Statement on the Unilateral Declaration of Independence made by the Catalan regional parliament; 27 de octubre de 2017. Acceso web al documento: https://www.gov.uk/ government/news/statement-on-udi-made-by-catalan-regional-parliament-27-october-2017 [consultado: 23/02/2019].

«How the World reacted to Catalan Independence Declaration»; Politico del 27/10/2017. Acceso web al documento: https://www.politico.eu/article/how-the-world-reacted-to-catalan-independence-declaration/ [consultado: 24/02/2019].

The Federal Chancellor, Catalonia declares the Independence; 28 de octubre de 2019. Acceso web al documento: https://www.bundeskanzlerin.de/bkin-en/news/-concern-at-anotherbreach-of-the-constitution--451342 [consultado: 23/02/2109]. 
feréndum del 1 de octubre de 2017 y la DUI, constituyó un decisivo revés internacional para la viabilidad del proyecto secesionista. A ello hay que sumarle la respuesta del Estado español aplicando el art. 155 de la Constitución y el procesamiento penal de los principales dirigentes independentistas catalanes.

La estrategia secesionista de Cataluña que se impulsó por los dirigentes independentistas durante los últimos meses de 2017, ha terminado en un rotundo fracaso por carecer de legalidad, nacional e internacional, y por el insuficiente apoyo popular en la propia Cataluña. Ello no significa que la inestabilidad política en esta región haya concluido y que la presión social independentista vaya a reducirse en un futuro próximo.

Probablemente la frustración ocasionada por este intento fallido, unido a las diferencias entre los partidos políticos nacionales sobre la estrategia a seguir para reducir la tensión con las instituciones y dirigentes catalanes, siga alimentando el conflicto durante los próximos años.

La reivindicación independentista catalana, al igual que la vasca, es real y ha alcanzado un apoyo social que resulta imposible ignorar políticamente por los poderes del Estado español. Visto desde la perspectiva actual, los hechos recientes demuestran que no basta con tener una aspiración legítima en un Estado de derecho y movilizarse políticamente para alcanzar el éxito en la secesión. Es imprescindible cumplir todos los requisitos y garantías que exige el orden jurídico interno y estar refrendado por el apoyo mayoritario de la ciudadanía tanto catalana como española. Un escenario que todavía no existe y que el reciente fracaso secesionista ha demorado históricamente. 